\title{
PARTNERSHIP FOR THE DEVELOPMENT OF KNOWLEDGE-BASED ECONOMY
}

\author{
Dan Coriolan Simedru \\ Vicepresident, Alba County Council
}

\begin{abstract}
The new global dynamics of the knowledge-based economy call for new economic and societal frameworks. Knowledge-based economy represents a challenge for Romania. The ways the scientific/academic organisations, private firms, financial institutions and public administration bodies create partnership arrangements to manage information, capital and human resources have a crucial impact in the next decade.
\end{abstract}

The new global dynamics of the knowledge-based economy call for new economic and societal frameworks. Knowledge-based economy represents a challenge for Romania. The ways the scientific/academic organisations, private firms, financial institutions and public administration bodies create partnership arrangements to manage information, capital and human resources have a crucial impact in the next decade.

The objective of the paper is to identify main issues which define the main features of the KBE in order to support the establishment of KBE network in the Alba County. This information may be useful to tune various understanding, approaches and professional agenda among the local partners interested to play a role in this field in the next couple of years.

The paper is a result of compiling the information collected from international bibliography, out of which the main are listed in the end of the paper. Results of the research of prestigious organisations such as The Organisation for Economic Co-operation and Development or United Nations Economic Commission for Europe we consider useful to use to achieve the objective of the paper.

The structure of the paper follows the idea of moving from definition of terms to the management aspects of KBE. Societies and economies are affected by globalisation and by the changes which occur in the area of knowledge and innovation. Information is available by the Internet and ICTs. Mobility of capitals, investments and products are going together with issues of environment damages and increasing poverty. The political and organisational activities, commitments and agreements have today global influence. All these are aspects of knowledge-based economy.

The question is how to organise ourselves to respond to the mentioned aspects. The paper starts presenting the key words which are: (1). Knowledge investments in research, education and training and new managerial capacity, (2). Knowledge distribution to help the development of the KBE partners such as employers, academic network and the industrial organisations.

As far as the political aspects are concern, the county policy should create appropriate policy to steer the process of guiding the local economy into a knowledge-based one. Appropriate policies should support basic research, the creation of mechanisms to enhance the social benefits of cooperation among researchers working in various organisations, and the last but not the least the investment in human capital.

The second aspect presented in the paper tackles the management issues. The chapters 3 present the areas towards firms should initiate and develop plans, and the new role of public administration in the knoweledge management. Building capacity for innovation and creativity, strengthening collaboration within the knowledge network and enhancing 
connectivity to markets represents for both public and private organisations common area to contribute for KBE.

The chapter 4 recommends some relevant steps to develop KBE, which are collected from the strategy of the development of the Knowledge-Based Economy in Armenia. The information presented may help the Alba KBE partners to build a platform to be publicly debated. 


\section{SETTING THE SCENE}

"KBE" will be the most important acronyms of the XXI century. The "knowledge-based economy" is one in which information and knowledge, rather than materials resources drive business activities while creating key sustainable competitive advantage.

The Organisation for Economic Co-operation and Development (OECD) released a report in 1996 entitled, "Knowledge-Based Economy" which categorically states that "knowledge is now recognised as the driver of productivity and economic growth.

The developed economies are increasingly based on knowledge and information. Knowledge is recognised as the driver of productivity and economic growth, leading to a new focus on the role of information, technology and learning in economic performance. The term "knowledge-based economy" stems from this fuller recognition of the place of knowledge and technology in modern economies.

The OECD report cites an estimate that more than 50\% of Gross Domestic Product (GDP) in the main OECD economies is now knowledge based. Across the OECD, investment in high technology goods and services is growing rapidly. Computers and related equipment are the fastest-growing elements of new tangible investments; the same goes with intangible investment in areas such as training, computer software and technical expertise.

Societies and economies are affected by globalisation and by the dynamics of knowledge and innovation. Data and information are available by the Internet and ICTs. Mobility of capitals, investments and products is increasing. Global issues of environment, poverty, security can not be classified as nation's aspects only. The international political and organisational activities, commitments and agreements have global influence. All these are aspects of knowledge-based economy.

The resource-and-technology-based economy is steadily moving into a knowledgedriven society, where science and technology cooperation impact productiveness and competitiveness of the economy, but also the research environment. The Science and Technology, considering knowledge as the main competitiveness asset, have a crucial role in improving local, regional, national and global welfare by offering solutions to needs and problems.

The new global dynamics of the knowledge-based economy call for new economic and societal frameworks. Innovation policies are no exception in this respect. The most developed societies such as European Union, United States, and Pacific developed countries, experiencing the current competitive pressure, decided to reshape their overall strategies on Science and Technology development policies.

Globalisation and Science and Technology (G/S\&T) as dominant components of the present and future development ask for synergic actions from all actors, if sustainable long term growth paths are on the political agenda. The $(\mathrm{G} / \mathrm{S} \& \mathrm{~T})$ pose new and more demanding challenges for the future, forcing countries to invent and follow the most suitable strategies, forcing the companies to and academic organisations to be part of the game.

\section{DEFINITION AND COMPONENTS OF KBE}

The term "knowledge-based economy" results from a fuller recognition of the role of knowledge and technology in economic growth. Knowledge, as embodied in human beings (as "human capital") and in technology, has always been central to economic development.

The OECD Paris, 1996 Report clarifies four terms it uses:

1. The knowledge-based economy is a term used to recognize the role of knowledge and technology in OECD economies. 
2. New growth theory is a term developed to explain the dynamics of the new economy.

3. Information society is a term, which reflects the growing role of the information management for the entire society.

4. Learning economy is a term which reflect the new working environment, stressing the role of continuous training.

The KBE partners should focus on the development performance and well-fare structured on the (1). Production, (2). Distribution, and (3). Use of knowledge and information, which call for high-technology investments, high-technology industries, highlyskilled labour and associated productivity and economic growth. The OECD report, mentioned before, organises knowledge accordingly in four categories:

1. Know-what refers to facts - the point at which knowledge is closest to information.

2. Know-why is scientific knowledge about the principles and laws of nature.

3. Know-how is the skill(s) or capability to do something.

4. Know-who involves knowing "who knows what and who knows how to do what".

\section{KNOWLEDGE MANAGEMENT AND PLAN}

The new global economy fuelled by information technology creates many opportunities and increased risks for businesses. Every firm "feels" the impact of changes which occur in the global economy, in the technology development which ask for continuous learning of competitiveness.

Knowledge Management (KM) and its appropriate application play a dominant role in shaping the business model of tomorrow. Every business organization is unique, faces different sets of challenges, and requires a unique solution for success. A firm's future success depends on:

- A deep understanding of the continuous shifts in business, economic, technological, and competitive environment.

- Its ability to create, build, and craft strategies in response to the business environment.

- Develop an appropriate business design that integrates organization structure and information systems with its strategic direction.

- Its capability to implement and execute its strategic and operational plans.

- Self-learning while it monitors its performance and change as needed.

To position into the present competitions economies and firms should initiate and develop actions towards the following areas:

- Building capacity to innovate and come up with new products and services for increasingly demanding customers.

- Strengthening Collaboration within the network with universities, research institutes, suppliers, customers to strengthen their access to new technologies, markets capabilities and talents.

- Enhancing Connectivity to markets.

The knowledge plan must review and analyze the firm's mission and objectives, organizational dynamics, knowledge assets, strategic approach, information systems, and the operation plan. It must then determine and develop action plans that identify what are the critical knowledge needs of the firm and how it should go about fulfilling that need. Tom Davenport, Professor of Information Management at the University of Texas and Larry Prusak, Managing Principal at IBM Consulting Group in Boston identified in the study 'Working Knowledge: How Organizations Manage What They Know' the following key aspects: 
"Knowledge of the Business Environment: It must provide the foundation of the state of the business environment on a continuous basis to all the levels of the economy/organization. Its purpose is to assess and examine the competitive environment, the potential shifts in the industry structure, technology impact, and understanding of the market forces that are shaping its working environment.

Knowledge of Strategic Thinking: All economies and businesses need to have strategies. The strategic model today is continuously changing. The knowledge management group has the responsibility to assist the firm to design and develop effective strategies. It must be able to provide a thorough but practical knowledge of latest strategic thinking concepts and analysis of real-world strategies of contemporary and competitive firms. It must bring the real world awareness to the organization.

Knowledge of Business Design: The implementation of strategy requires a complimentary business design. Business design implies an appropriate organization structure integrated with the firm's information system.

Knowledge management must facilitate the process of creating the right business model. It must evaluate and recommend different models that allow the economy/firm to create the best model for its competitive position.

Implementation Knowledge: Any strategy should provide means for its implementation. Knowledge management must create methodologies to monitor and measure the business performance and recommend changes as and when needed. Every firm should have a knowledge resource backup, as a foundation for knowledge acquisition on relevant and contemporary business, management, economic, and strategic topics and issues".

Tom Davenport, Professor of Information Management at the University of Texas and Larry Prusak, Managing Principal at IBM Consulting Group in Boston, in 1998 published their work, 'Working Knowledge: How Organizations Manage What They Know'. Based, as it is, on extensive research into management practice, Davenport and Prusak's book presents a pragmatic approach to knowledge management.

Tom Davenport et. al. in their published research paper on "Successful Knowledge Management Projects" identify what might be a likely success factors for an organization wishing to build effective knowledge management projects:

1. Link to economic performance or industry value

2. Technical and organizational infrastructure

3. Standard, flexible knowledge structure

4. Knowledge-friendly culture

5. Clear purpose and language

6. Change in motivational practices

7. Multiple channels for knowledge transfer

8. Senior management support

It is our role to forsee for the economic developemnt of the Alba county how and in which sequence we can apply the success factors not for one organisation but for the all partners interested to contribute in the development of a KBE. To build the sustainable KBE development in Alba County, the administration should adapt to the competitions as well, by creating a competitive internal management, working close to research institutions, and link public policies with the market features. The mission of local knowledge management must be to provide all the necessary knowledge that it needs to create a sustainable competitive advantage for the county. 


\section{PARTNERSHIP TOWARDS KBE / RECOMMENDATION ${ }^{1}$}

The long-term objectives towards a knowledge-based economy should encompass:

- the creation of a vibrant and sustainable ICT industry that promotes growth in other sectors of economy;

- the inclusion in the knowledge-based national and global economy.

The following conditions are essential for the development of a successful ICT industry:

- the retention of skilled human capital as the key to competitiveness;

- the provision of access to capital and the market for emerging ICT businesses.

One focal point is the establishment of a business incubator, which will provide small and medium ICT enterprises with: management and marketing training; access to credit; and, access to foreign markets. Other focal points include:

- the support of an active national ICT association that caters for all aspects of the sector's development;

- the promotion of a productivity programme to upgrade initiatives with ICT at their centre, developing simultaneous both the market and businesses capable of supplying goods and services to it;

- the implementation of cluster development programmes to improve business capabilities, starting with the ICT sector.

Significant parts of the ICT Master Strategy address the issues of a favourable investment climate, and of the regulatory framework which supports the growth of an ICT industry. In accordance with the Master Strategy, the following tasks are to be accomplished by the government in order to ensure an investment-friendly environment and favourable legislation:

- the identification of a trade policy that encourages investment and local business development by focusing on simplified customs rules and regulations;

- the improvement of delivery services for both domestic and international products and of services facilitating e-commerce;

- the adoption of a comprehensive and standardised classification system and clearance procedure;

- the establishment of more detailed statutory regulations for the conclusion and enforcement of electronic contracts, as well as for the use of electronic signatures.

The maintenance and further developing of the human capital by strengthening the educational system and building an effective innovation system are crucial and should be divided into sections as follows:

- the building of a market-oriented higher education system;

- the introduction of computer literacy programs to different categories of state and private sector employees;

- the creation of training courses for the unemployed in order to provide them with employment opportunities in the new economy.

- the availability of a reliable high-speed Internet broadband connection to support remote educational systems, including distance learning software support systems, digital library access systems and logistics support systems;

- the provision of reliable and rapid forms of communication between local \& national \& international academic institutions.

\section{Bibliography}

\footnotetext{
1 / Recommendations are adapted from ARMENIA-COUNTRY READINESS ASSESSMENT REPORT, UNITED NATIONS ECONOMIC COMMISSION FOR EUROPE -2002.
} 
- Organisation for economic co-operation and development, The knowledge-based economy, paris 1996

- Davenport, t., de long d., and beers, m. , "Successful knowledge management projects", sloan management review, winter 1998

- United nations economic commission for europe, towards a knowledge-based economy/Armenia, country readiness assessment report, 2002. 